\title{
Resistance Study of Er-doped Zinc Oxide Diode by Spray Pyrolysis
}

\author{
Tzu-Hsiang Lin, ${ }^{1}$ Wen-How Lan, ${ }^{1 *}$ Ming-Chang Shih, ${ }^{1}$ Mu-Chun Wang, ${ }^{2 * *}$ \\ Kuo-Jen Chang, ${ }^{3}$ Jia-Ching Lin, ${ }^{3}$ Shao-Yi Lee, ${ }^{3}$ Wen-Jen Lin, ${ }^{3}$ and Chien-Jung Huang ${ }^{4}$ \\ ${ }^{1}$ Department of Electrical Engineering, National University of Kaohsiung, \\ No. 700, Kaohsiung University Road, Nan-tzu District, Kaohsiung 81148, Taiwan (R.O.C.) \\ ${ }^{2}$ Department of Electronic Engineering, Minghsin University of Science and Technology, \\ No. 1, Xinxing Rd., Xinfeng Township, Hsinchu 30401, Taiwan (R.O.C.) \\ ${ }^{3}$ National Chung-Shan Institute of Science \& Technology, \\ No. 481, Zhongzheng Rd., Longtan District, Taoyuan 32546,Taiwan (R.O.C.) \\ ${ }^{4}$ Department of Applied Physics, National University of Kaohsiung, \\ No. 700, Kaohsiung University Rd., Nan-tzu District, Kaohsiung 81148, Taiwan (R.O.C.)
}

(Received November 17, 2017; accepted January 18, 2018)

Keywords: resistance, zinc oxide, erbium

Undoped and erbium-doped zinc oxide followed by indium-doped zinc oxide layers on p-type Si substrate were prepared by spray pyrolysis with zinc acetate, erbium acetate, and indium nitrate precursors. The surface morphology and crystalline quality were investigated. Using a front- and back-side metallization process, diodes were fabricated. The current-voltage characteristics of these diodes were analyzed. The structural resistance, which is an important issue in gas sensing application, shows an increase-decrease behavior with the increase of erbium contents in zinc oxide. With a reverse bias in excess of $6 \mathrm{~V}$, two distinct green light emissions with 536 and $555 \mathrm{~nm}$ wavelength and one red light emission at around $664 \mathrm{~nm}$ of the $5 \%$ erbium-doped zinc oxide diode can be observed. The structural resistance character, as well as the ideality factor of these diodes were analyzed and discussed.

\section{Introduction}

Zinc oxide (ZnO), a group II-VI semiconductor with high melting temperature, ${ }^{(1)}$ wide bandgap, ${ }^{(2)}$ and large exciton binding energy, ${ }^{(3)}$ has attracted much attention in the past decade. Many ZnO-based devices have been investigated. ${ }^{(4-9)}$ In the device structure, the doping in the film is an important issue in the material and device performance. Rare-earth erbium (Er) doping, which improves the resistance response ${ }^{(10,11)}$ of $\mathrm{ZnO}$ in different gases, has been applied in many gas sensing devices. ${ }^{(12,13)}$ Meanwhile, with the carrier transitions between the ionized Er energy states, ${ }^{(14,15)}$ photon emissions can be observed. ${ }^{(16,17)}$ These Er-related emissions occurred from the energy transformation of electron-hole pairs and/or electron impact to Er ion under suitable voltage bias. ${ }^{(18,19)}$

\footnotetext{
*Corresponding author: e-mail: whlan@nuk.edu.tw

${ }^{* *}$ Corresponding author: e-mail: mucwang@must.edu.tw http://dx.doi.org/10.18494/SAM.2018.1809
} 
In the fabrication of $\mathrm{ZnO}$ thin film, many deposition methods such as molecular beam epitaxy, ${ }^{(20)}$ chemical vapor deposition, ${ }^{(21)}$ sputtering, ${ }^{(22)}$ sol-gel, ${ }^{(23)}$ and spray pyrolysis ${ }^{(24)}$ have been developed. The spray pyrolysis method, which is one of the nonvacuum techniques, shows potential for easy scale up.

In our previous study, we examined the conduction type and concentrations of the Erdoped $\mathrm{ZnO}$ thin films. In this work, we report the electrical properties of the $\mathrm{p}-\mathrm{Si} / \mathrm{n}-\mathrm{ZnO}: \mathrm{Er}$ heterojunction diode with different Er contents by spray pyrolysis. The effects of Er doping, diode resistance, ideality factor, and electroluminescence properties were discussed.

\section{Experimental Details}

$\mathrm{ZnO}: \mathrm{Er} / \mathrm{ZnO}: \mathrm{In}$ diodes with different Er contents were grown on $\mathrm{p}$-Si [(111), $5 \times 10^{18}$ $\mathrm{cm}^{-3}$ ] substrates by spray pyrolysis deposition. ${ }^{(24)}$ Aqueous solutions containing zinc acetate $\left[\mathrm{Zn}\left(\mathrm{CH}_{3} \mathrm{COOH}\right)_{2} \cdot 2 \mathrm{H}_{2} \mathrm{O}\right]$, erbium acetate $\left[\mathrm{Er}\left(\mathrm{CH}_{3} \mathrm{COO}\right)_{3} \cdot 4 \mathrm{H}_{2} \mathrm{O}\right]$, and indium nitrate $\left[\mathrm{In}\left(\mathrm{NO}_{3}\right)_{3} \cdot 5 \mathrm{H}_{2} \mathrm{O}\right]$ were used as precursors in the fabrication of $\mathrm{ZnO}: \mathrm{Er}$ and $\mathrm{ZnO}: \mathrm{In}$ layers. The $\mathrm{Zn}$ concentration was fixed at $0.2 \mathrm{M}$ in precursors. Before deposition, the aqueous solution was stirred for one hour at room temperature to yield a clear solution. In the $\mathrm{ZnO}$ : Er layer, the atomic ratios of $\mathrm{Er}$ to $\mathrm{Zn}$ in the precursor were $0,1,5$, and $10 \% .{ }^{(25)}$ In the $\mathrm{ZnO}$ :In layer, the atomic ratio of $\mathrm{In}$ to $\mathrm{Zn}$ in the precursor was $5 \%$ for all samples. The deposition temperature was $450{ }^{\circ} \mathrm{C}$. The thicknesses of $\mathrm{ZnO}: \mathrm{Er}$ and $\mathrm{ZnO}$ :In are around 400 and $40 \mathrm{~nm}$, respectively. The concentration of ZnO:In was around $5 \times 10^{18} \mathrm{~cm}^{-3}$. After the film deposition, In was deposited on the backside of Si using a thermal coater. The front Au circular pads of $0.8 \mathrm{~mm}$ diameter were achieved with a shadow mask on the $\mathrm{ZnO}$ :In surface by direct-current magnetron sputtering. The samples with different Er contents were then indexed as S0, S1, S2, and S3.

The surface morphology of the films was examined by scanning electron microscopy (SEM, HITACHI S-4300N). The crystalline property was examined by X-ray diffraction (XRD, Bruker D8). The photoluminescence (PL) measurement was accomplished using an optical system with a spectrometer (Ocean, HR2000+), a He-Cd laser (325 nm wavelength) as the light source, and a temperature-controlled cryogenic system. The source meter (Keithley 2400) was applied in the device current-voltage measurement.

\section{Results and Discussion}

Figure 1 shows the XRD pattern of the $\mathrm{ZnO}$ diodes with different Er contents in the active region. The observed peaks at $34.46,36.28$, and $31.82^{\circ}$ were attributed to $\mathrm{ZnO}(002)$, (101), and (100) planes, respectively. No Er-oxide-related peaks ${ }^{(26,27)}$ can be observed. With the increase in Er content, the intensity ratio of (002) to (100) increased and thus the crystalline property varied.

Figure 2 shows the surface morphology of the diodes (a) without Er doping (S0), (b) with 1\% Er doping (S1), (c) with 5\% Er doping (S2), and (d) with 10\% Er doping (S3). For sample S0, the morphology of flakes with different sizes can be observed. With the increase in Er doping content, the number of tiny flakes increases. The result of surface morphology variation is 


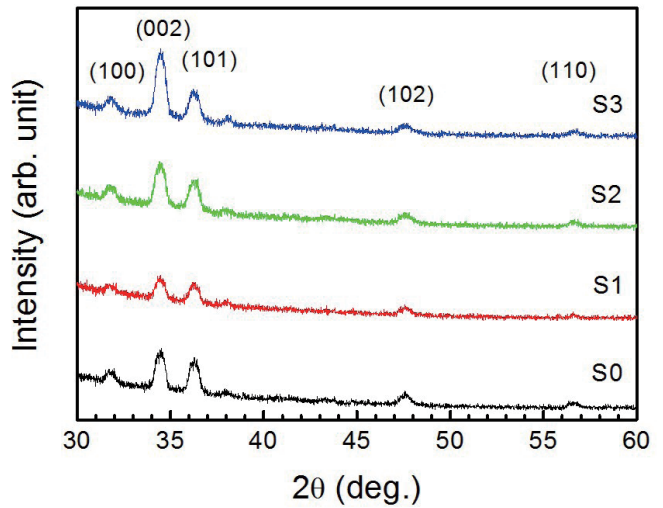

Fig. 1. (Color online) XRD patterns of $\mathrm{ZnO}$ diodes without Er doping (S0), with 1\% Er doping (S1), with 5\% Er doping (S2), and with 10\% Er doping (S3).

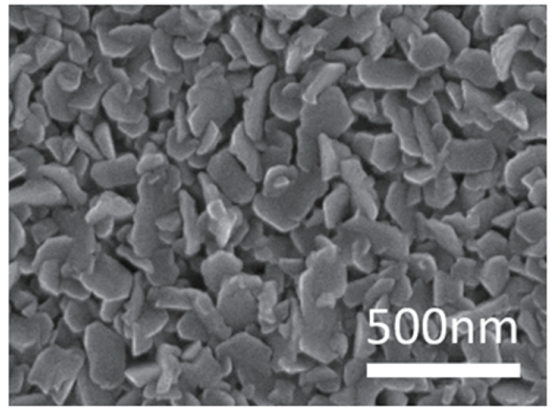

(a)

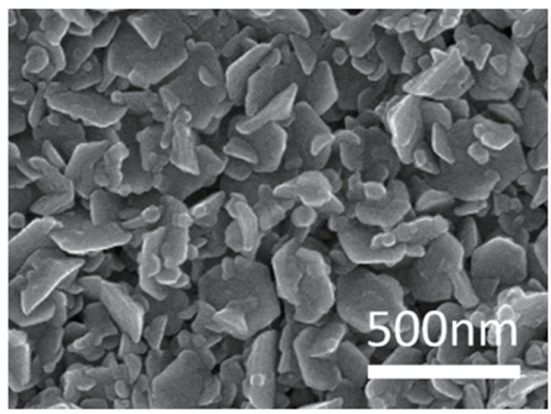

(c)

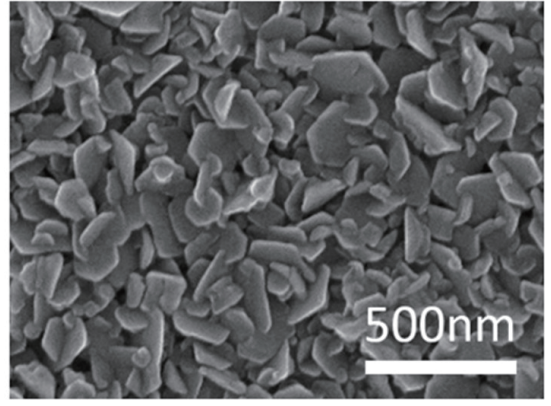

(b)

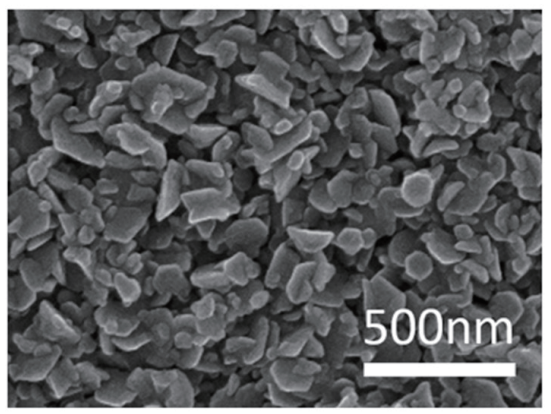

(d)

Fig. 2. SEM images of the $\mathrm{ZnO}$ diodes (a) without Er doping (S0), (b) with 1\% Er doping (S1), (c) with 5\% Er doping (S2), and (d) with $10 \%$ Er doping (S3).

consistent with the reported grain size shrinkage behavior for the $\mathrm{ZnO}$ films with the increase in Er doping content. ${ }^{(18)}$

Figure 3 shows the 10K PL spectrum of the $\mathrm{ZnO}$ diodes. For sample S0, a near-band-edge emission with a peak wavelength of $369.1 \mathrm{~nm}(3.360 \mathrm{eV})$ can be observed. This emission is attributed to the recombination of excitons bound to neutral donor $\left(\mathrm{D}^{\circ} \mathrm{X}\right)$ and is labeled as bound exciton complexes (denoted as BEC). Another emission band with a wavelength of 373.7 


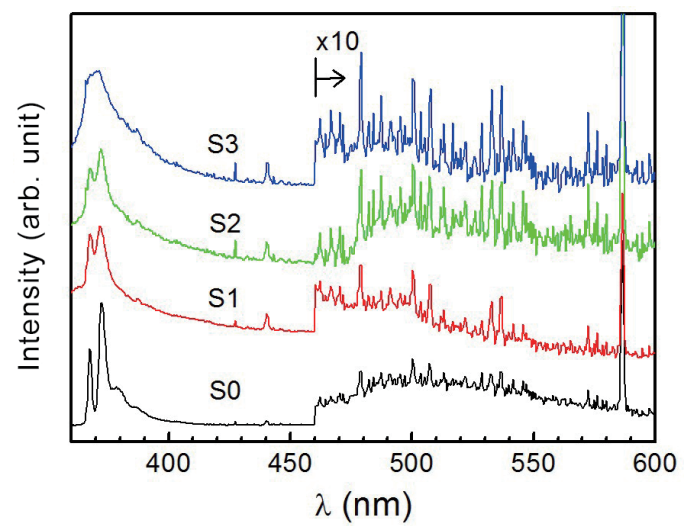

Fig. 3. (Color online) 10K photoluminescence spectrum of $\mathrm{ZnO}$ diodes without Er doping (S0), with 1\% Er doping (S1), with 5\% Er doping (S2), and with 10\% Er doping (S3).

$\mathrm{nm}(3.318 \mathrm{eV})$ can be observed. This emission, which is around $40 \mathrm{meV}$ below the BEC band, originates from the two electron satellite (denoted as TES) transitions of the $\mathrm{D}^{0} \mathrm{X}^{(28,29)}$ The emission band with a wavelength of $382 \mathrm{~nm}(3.246 \mathrm{eV})$, which is $72 \mathrm{meV}$ below TES, is the phonon replica of the TES band (denoted as TES-LO). The emission band with a wavelength of $386.0 \mathrm{~nm}(3.21 \mathrm{eV})$, which can be observed in some unintentionally doped $\mathrm{ZnO}$, is attributed to the donor-acceptor pair (denoted as DAP) ${ }^{(29)}$ and/or another TES transition due to a second donor with a different binding energy. ${ }^{(30)}$ Besides, a broad band emission in the wavelength region $460-550 \mathrm{~nm}$ can be observed. This band is the combination of deep levels such as ionized oxygen vacancy $\left[\mathrm{V}_{\mathrm{O}}{ }^{+}\right],{ }^{(31,32)}$ zinc interstitial state $\left[\mathrm{Zn}_{\mathrm{i}}\right],{ }^{(33)}$ oxygen antisite state $\left[\mathrm{O}_{\mathrm{Zn}}\right],{ }^{(34)}$ oxygen interstitial level $\left[\mathrm{O}_{\mathrm{i}}\right],{ }^{(31)}$ and zinc vacancy-related transitions. ${ }^{(34,35)}$

For samples S1 and S2, with the introduction of Er, the BEC band with a peak wavelength of $373.7 \mathrm{~nm}$ as sample S0 can be identified. Besides, an emission band with a peak wavelength of $373.2 \mathrm{~nm}(3.323 \mathrm{eV})$ can be observed. For $\mathrm{Zn}$ with Er doping, although there is no obvious PL emission band, ${ }^{(36)}$ the incorporation of Er may alter the binding energy of $\mathrm{D}^{\circ} \mathrm{X}^{(25)}$ and cause the energy shift of the TES band. These reveal that the bonding environment varies. For sample S3, with more Er causing binding state variation, a broad near-band-edge emission as the combination of BEC and TES can be observed. Two broad bands around 470-520 nm (denoted as CE) and 510-550nm (denoted as GE) can be observed for the Er-doped samples. The CE band, with the corresponding energy of $2.5 \mathrm{eV}$, is identified as $\left[\mathrm{V}_{\mathrm{O}}{ }^{+}\right]^{(31,32)}$ and/or $\left[\mathrm{Zn}_{\mathrm{i}}\right]{ }^{\left({ }^{(3)}\right)}$ The GE band, with the corresponding energy around $2.3 \mathrm{eV}$, is attributed to $\mathrm{O}_{\mathrm{Zn}},{ }^{\left({ }^{(3)}\right.} \mathrm{O}_{\mathrm{i}}{ }^{(31)}$ and/or the zinc vacancy-related transitions. ${ }^{(34,35)}$ Thus, the incorporation of Er into the $\mathrm{ZnO}$ may alter the structural binding state of the $\mathrm{ZnO}$.

Figure 4 shows the current-voltage $(I-V)$ characteristics of these $\mathrm{ZnO}$ diodes at room temperature. A rectification character in forward bias and breakdown behavior in reverse bias can be observed.

For a diode with the series resistance $R s$, the diode $I-V$ character is ${ }^{(36)}$

$$
I=I_{0}\left(e^{\frac{q(V-I \times R s)}{n k_{B} T}}-1\right)
$$




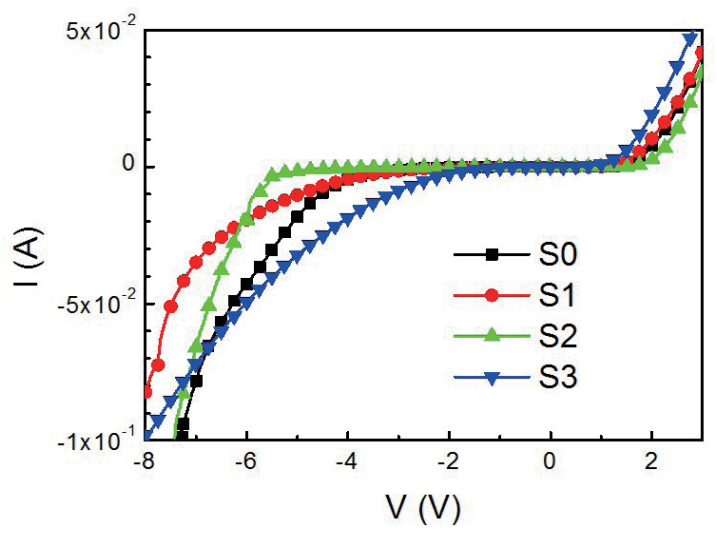

Fig. 4. (Color online) $I-V$ characteristics of the $\mathrm{ZnO}$ diodes without Er doping (S0), with 1\% Er doping (S1), with $5 \%$ Er doping (S2), and with 10\% Er doping (S3).

where $I_{0}$ is the reverse saturation current, $q$ is the electronic charge, $k_{B}$ is the Boltzmann constant, $T$ is the temperature, and $n$ is the ideality factor. To extract $n$ and $R s$ from the $I-V$ character, one can rearrange the equation to

$$
I \frac{d V}{d I}=\frac{n k_{B} T}{q}+I \times R s
$$

Then, $n$ and $R s$ can be extracted using the plot of $I d V / d I-I$ from the intercept and slope. Figure 5 shows the $I d V / d I-I$ plot of the diodes. The extracted $n$ and $R s$ are listed in Table 1. For the 1\% Er-doped $\mathrm{ZnO}$ the high $R s$ value can be observed. The incorporated Er ions may alter the bonding environment as shown in Fig. 3 and thus inhibit the carrier concentration ${ }^{(25)}$ generated from native defects. The reduction-of-defect effect may cause the high ethanol gas sensor response for the 1\% Er-doped $\mathrm{ZnO}^{(13)}$ With the increase in Er content higher than $1 \%$ in $\mathrm{ZnO}$, the carrier concentration increases as the interstitial of Er to $\mathrm{Zn}$ occurred, and $R s$ decreases to $20.5 \Omega$ (S3). For the ideality factor $n$, a quantity greater than 2 can be observed for all samples; $n$ is 1 for the recombination of injected carriers in the neutral region and 2 for the carrier recombination by mediated recombination centers in the space charge region. ${ }^{(37,38)}$ The ideality factor $n$ greater than 2 reveals more recombination paths and the diode is far from being ideal. $^{(39)}$ For the heterostructured diode in this work, the high ideality may be caused by the effect of heterojunction ${ }^{(40)}$ and/or the high defect density ${ }^{(18)}$ in the $\mathrm{ZnO}: \mathrm{Er}$ film.

For the Er-doped diodes operated in reverse bias, a green light emission can be observed with a certain injection current. Figure 6 shows the electroluminescence spectra of samples S1, S2, and S3 with a reverse-biased injection current of $100 \mathrm{~mA}$ at room temperature. The inset shows a photo of light emission for sample S2. With spectral measurement, three emission bands in the visible range can be observed. For the diode under reverse bias, as the concentration of $\mathrm{p}$-Si $\left(5 \times 10^{18} \mathrm{~cm}^{-3}\right)$ is higher than the electron concentration of $\mathrm{ZnO}: \mathrm{Er}$, the depletion region of the diode is mainly in the $\mathrm{ZnO}: \mathrm{Er}$ region. The electron-hole pairs, which were created and accelerated in the depletion region by the high electric field, transfer the energy to excite 


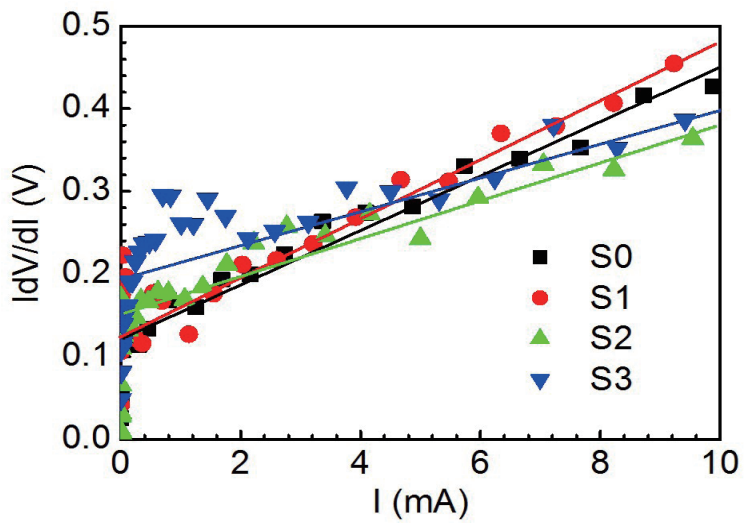

Fig. 5. (Color online) $I d V / d I-I$ plot of the $\mathrm{ZnO}$ diodes with different Er contents at room temperature.

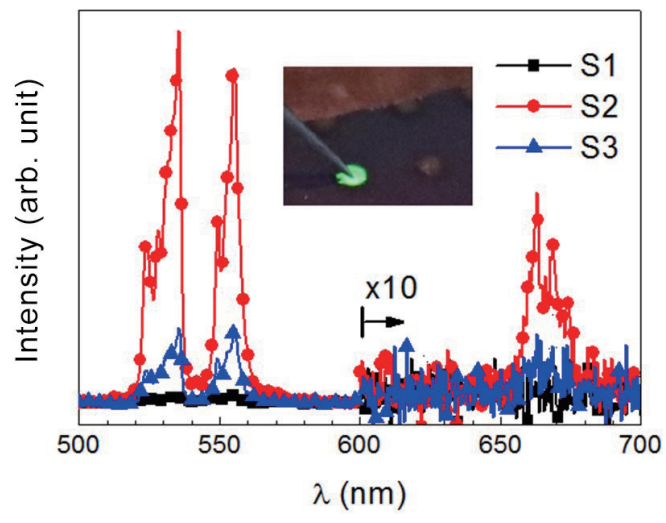

Fig. 6. (Color online) Electroluminescence spectra of the Er doped $\mathrm{ZnO}$ diode samples S1, S2, and S3 with $100 \mathrm{~mA}$ injection current at room temperature. The inset shows the photo of light emission for sample S2.

Table 1

Structure, ideality factor $(n)$, and series resistance $(R s)$ of the $\mathrm{ZnO}$ diode with different Er contents. The ratio of $\mathrm{Er} / \mathrm{Zn}$ in the precursor is shown in the parentheses.

\begin{tabular}{lccc}
\hline Sample & Structure & $R s(\Omega)$ & $n$ \\
\hline S0 & p-Si/ZnO/ZnO:In & 33.5 & 4.5 \\
S1 & p-Si/ZnO:Er(1\%)/ZnO:In & 35.6 & 4.5 \\
S3 & p-Si/ZnO:Er(5\%)/ZnO:In & 22.9 & 5.8 \\
S4 & p-Si/ZnO:Er(10\%)/ZnO:In & 20.5 & 7.5 \\
\hline
\end{tabular}

Er ions by impact ionization ${ }^{(41,42)}$ and cause the emissions of the diode. The emission bands are related to the energy state transitions of $\mathrm{Er}^{3+}$ of ${ }^{2} \mathrm{H}_{11 / 2} \rightarrow{ }^{4} \mathrm{I}_{15 / 2}(520-540 \mathrm{~nm}),{ }^{4} \mathrm{~S}_{3 / 2} \rightarrow{ }^{4} \mathrm{I}_{15 / 2}$ $(549-555 \mathrm{~nm})$, and ${ }^{4} \mathrm{~F}_{9 / 2} \rightarrow{ }^{4} \mathrm{I}_{15 / 2}(650-670 \mathrm{~nm}) .{ }^{(43)}$ The fine structure in the emission band is caused by the variation of the host structure. ${ }^{(4)}$ In sample S1, the weak emission intensity may be caused by the low Er content. With the increase in Er content in the diode, the intensity of sample S2 increases and three emission bands can be observed. For sample S3, the intensity decreases and only two emission bands can be observed. The red emission band (650-670 nm) cannot be observed for the diode with high defect density. ${ }^{(45)}$ This reveals the degradation of the film quality of sample S3 and is consistent with the broad near-band-edge emission of PL characterization in Fig. 3.

\section{Conclusions}

The properties of $\mathrm{p}-\mathrm{Si} / \mathrm{ZnO}: \mathrm{Er} / \mathrm{ZnO}$ :In diodes with various Er doping contents prepared by spray pyrolysis were studied. The surface morphology and crystalline quality were investigated. With the increase in Er content into $\mathrm{ZnO}$, a broad near-band-edge emission and varied deep-level emissions in PL spectra were characterized. The rectified $I-V$ behavior of the diodes was characterized. High diode resistance for $1 \%$ Er-doped $\mathrm{ZnO}$ in the active region with the inhibition of carrier concentration caused from defects shows extensive potential in 
sensor application. With the increase of Er content higher than $1 \%$ in the active region, diode resistance decreases, and the incorporation of Er doping also induces certain defect states in the active region. This causes the high ideality factor behavior and thus reduces the diode luminescence efficiency.

\section{Acknowledgments}

This research was supported by the Ministry of Science and Technology, Taiwan (MOST 104-2221-E-390-011-MY2, MOST 106-2221-E-390-012), and National Chung Shan Institute of Science and Technology, R.O.C. [NCSIST-103-V304(106)].

\section{References}

$1 \quad$ X. Su, Z. Zhang, and M. Zhu: Appl. Phys. Lett. 88 (2006) 061913.

2 R. A. Wahyuono, F. Hermann-Westendorf, A. Dellith, C. Schmidt, J. Dellith, J. Plentz, M. Schulz, M. Presselt, M. Seyring, M. Rettenmeyer, and B. Dietzek: Chem. Phys. 483 (2017) 112.

3 D. A. Lucca, D. W. Hamby, M. J. Klopfstein, and G. Cantwell: Phys. Status Solidi B 229 (2002) 845.

4 H. Yamauchi, M. Iizuka, and K. Kudo: Jpn. J. Appl. Phys. 46 (2007) 2678.

5 D. Choi, M. Y. Choi, W. M. Choi, H. J. Shin, H. K. Park, J. S. Seo, J. Park, S. M. Yoon, S. J. Chae, Y. H. Lee, S. W. Kim, J. Y. Choi, S. Y. Lee, and J. M. Kim: Adv. Mater. 22 (2010) 2187.

6 Z. T. Salim, U. Hashim, M. K. M. Arshad, M. A. Fakhri, and E. T. Salim: Mater. Res. Bull. 86 (2017) 215.

7 J. H. Lim, C. K. Kang, K. K. Kim, I. K. Park, D. K. Hwang, and S. J. Park: Adv. Mater. 18 (2006) 2720.

8 F. H. Nicoll: Appl. Phys. Lett. 9 (1966) 13.

9 K. V. Gurav, M. G. Gang, S. W. Shin, U. M. Patil, P. R. Deshmukh, G. L. Agawane, M. P. Suryawanshi, S. M. Pawar, P. S. Patil, C. D. Lokhandeb, and J. H. Kim: Sens. Actuators, B 190 (2014) 439.

10 X. H. Zhang, J. Chen, Y. Wu, Z. Xie, J. Kang, and L. Zheng: Colloids Surf., A 384 (2011) 580.

11 A. Hastir, N. Kohli, and R.C. Singh: J. Phys. Chem. Solids 105 (2017) 23.

12 B. S. Cao, L. Rino, J. L. Wu, Y. Y. He, Z. Y. Zhang, Z. Q. Feng, and B. Dong: Sens. Actuators, A 268 (2017) 110.

13 Y. Sun, Z. Zhao, P. Li, G. Li, Y. Chen, W. Zhang, and J. Hu: Appl. Surf. Sci. 356 (2015) 73.

14 J. C. Ronfard-Haret, J. Kossanyia, and J. L. Pastol: J. Phys. Chem. Solids 62 (2001) 565.

15 S. Harako, S. Yokoyama, K. Ide, X. Zhao, and S. Komoro: Phys. Status Solidi A 205 (2008) 19.

16 M. Llusca, J. Lopez-Vidrier, S. Lauzurica, M. I. Sanchez-Aniorte, A. Antony, C. Molpeceres, S. Hernandez, B. Garrido, and J. Bertomeu: J. Lumin. 167 (2015) 101.

17 J. C. Ronfard-Haret, J. Kossanyi, and J. L. Pastol: J. Phys. Chem. Solids 62 (2001) 565.

18 S. Iwan, S. Bambang, J. L. Zhao, S. T. Tan, H. M. Fan, L. Sun, S. Zhang, H. H. Ryu, and X. W. Sun: Physica B 407 (2012) 2721.

19 F. Vetrone, J. C. Boyer, J. A. Capobianco, A. Speghini, and M. Bettinelli: Appl. Phys. Lett. 80 (2002) 1752.

20 D. M. Bagnall, Y. F. Chen, M. Y. Shen, Z. Zhu, T. Goto, and T. Yao: J. Cryst. Growth 184 (1998) 605.

21 X. Duan, G. Chen, L. Guo, Y. Zhu, H. Ye, and Y. Wu: Superlattices Microstruct. 88 (2015) 501.

22 T. Shiosaki, S. Ohnishi, and A. Kawabata: J. Appl. Phys. 50 (1979) 3113.

23 L. Spanhel and M. A. Anderson: J. Am. Chem. Soc. 113 (1991) 2826.

24 Y. T. Hsu, W. H. Lan, K. F. Huang, J. C. Lin, and K. J. Chang: Physica B 481 (2016) 63.

25 T. H. Lin, Y. F. Lu, Y. H. Chen, W. H. Lan, M. C. Shih, M. C. Wang, J. C. Lin, K. J. Chang, and W. J. Lin: IEEE Int. Symp. Next-Generation Electronics 2016, Taiwan (2016) 7167.

26 V. Mikhelashvili, G. Eisenstein, and F. Edelmann: Appl. Phys. Lett. 80 (2002) 2156.

27 D. Levchuk, S. Levchuk, H. Maier, H. Bolt, and A. Suzuki: J. Nucl. Mater. 367 (2007) 1033.

28 A. Teke, U. Ozgur, S. Dogan, X. Gu, and H. Morkoc: Phys. Rev. B 70 (2004) 195207.

29 B. K. Meyer, H. Alves, D. M. Hofmann, W. Kriegseis, D. Forster, F. Bertram, J. Christen, A. Hoffmann, M. Strabburg, M. Dworzak, U. Haboeck, and A. V. Rodina: Phys. Status Solidi, B 241 (2004) 231.

30 K. Thonke, T. Gruber, N. Teofilov, R. Schonfelder, A. Waag, and R. Sauer: Physica B 308 (2001) 945.

31 A. C. Rastogi, S. B. Desu, P. Bhattacharya, and R. S. Katiyar: J. Electroceramics 13 (2004) 345.

32 J. C. Fan, K. M. Sreekanth, Z. Xie, S. L. Chang, and K. V. Rao: Prog. Mater. Sci. 58 (2013) 847. 
33 J. C. Sun, H. W. Liang, and J. Z. Zhao: Chem. Phy. Lett. 460 (2008) 548.

34 A. S. Gadallah and M. M. E. Nahass: Adv. Condens. Matter Phys. 1 (2013) 234546.

35 S. Golshahi, S. M. Rozati, R. Martins, and E. Fortunato: Thin Solid Films 518 (2009) 1149.

36 E. Fred Schubert: Light-Emitting Diodes (Cambridge University Press, New York, 2006) 2nd ed., p. 64.

37 J. M. Shah, Y. L. Li, T. Gessmann, and E. F. Schubert: J. Appl. Phys. 94 (2003) 2627.

38 C. T. Sah, R. N. Nyoce, and W. Shockley: Proc. IRE (1957) 1228.

39 N. Zebbar, Y. Kheireddine, K. Mokeddem, A. Hafdallah, M. Kechouane, and M. S. Aida: Mater. Sci. Semicond. Process. 14 (2011) 229.

40 D. Zhu, J. Xu, A. N. Noemaun, J. K. Kim, E. F. Schubert, M. H. Crawford, and D. D. Koleske: Appl. Phys. Lett. 94 (2009) 081113.

41 J. M. Langer, A. Lemanska-Bajorek, and A. Suchocki: Appl. Phys. Lett. 39 (1981) 386.

42 G. Franzo, S. Coffa, F. Priolo, and C. Spinella: J. Appl. Phys. 81 (1997) 2784.

43 S. Prucnal, L. Rebohle, and W. Skorupa: J. Non-Cryst. Solids 357 (2011) 915.

44 A. Polman: Physica B 300 (2001) 78.

45 S. Harako, S. Yokoyama, K. Ide, X. Zhao, and S. Komoro: Phys. Status Solildi A 205 (2008) 19. 